\title{
Current management of liver metastases from gastric cancer: what is common practice? New challenge of EORTC and JCOG
}

\author{
Kozo Kataoka1 $^{1}$ (D) Takahiro Kinoshita ${ }^{2} \cdot$ Markus Moehler $^{3} \cdot$ Murielle Mauer $^{1}$ • \\ Kohei Shitara $^{4}$ - Anna Dorothea Wagner ${ }^{5}$ - Stefanie Schrauwen ${ }^{1}$ Takaki Yoshikawa ${ }^{6}$. \\ Franco Roviello $^{7} \cdot$ Masanori Tokunaga $^{8} \cdot$ Narikazu Boku' $^{9}$ Michel Ducreux ${ }^{10}$. \\ Masanori Terashima ${ }^{8}$. Florian Lordick $^{11} \cdot$ On behalf of EORTC GITCG Group and \\ JCOG SCGC Group
}

Received: 21 November 2016/Accepted: 18 January 2017/Published online: 1 February 2017

(c) The International Gastric Cancer Association and The Japanese Gastric Cancer Association 2017

\begin{abstract}
The role of multidisciplinary treatment including surgery for liver metastases from gastric cancer (LMGC) is controversial. Studies to answer this clinical question are increasing in number, but all published data thus far are based on retrospective analyses with limited sample sizes. Thus, the European Organisation for Research and Treatment of Cancer (EORTC) Gastrointestinal Tract Cancer Group (GITCG) and the Japan Clinical Oncology Group (JCOG) Stomach Cancer Study Group (SCSG) initiated a collaboration to develop an optimal treatment strategy for LMGC. Before planning a prospective study, a questionnaire was sent out to the network members of both groups in June 2016 to clarify current common practice in each region. Sixty-seven sites from 17 countries in the EORTC
\end{abstract}

Electronic supplementary material The online version of this article (doi:10.1007/s10120-017-0696-7) contains supplementary material, which is available to authorized users.

Kozo Kataoka

kozokataoka@hotmail.co.jp

$\bowtie$ Florian Lordick

florian.lordick@medizin.uni-leipzig.de

1 European Organisation for Research and Treatment of Cancer (EORTC) Headquarters, Avenue E, Mounier 83/11, 1200 Brussels, Belgium

2 Department of Gastric Surgery Division, National Cancer Center Hospital East, Chiba, Japan

3 First Department of Internal Medicine, Johannes GutenbergUniversity of Mainz, Mainz, Germany

4 Department of Gastroenterology and Gastrointestinal Oncology, National Cancer Center Hospital East, National Cancer Center Hospital East, Chiba, Japan

5 Department of Oncology, Lausanne University Hospital, Lausanne, Switzerland network and 55 sites from Japan responded. According to the survey, for patients with resectable LMGC without extrahepatic metastases, preoperative chemotherapy followed by resection of both primary (if still in place) and liver lesions was the preferred option for both the synchronous and the metachronous setting. For patients with unresectable LMGC, most of the sites recommended chemotherapy only. In this article, the detailed results of this survey are reported, shedding light on current community practice, and a joint EORTC-JCOG strategy of investigation is delineated.

Keywords Gastric cancer · Liver metastases · Surgery · EORTC $\cdot$ JCOG 


\section{Introduction}

Gastric cancer (GC) is the third leading cause of cancerrelated death worldwide [1]. Surgery is the mainstay of multimodality treatment for localized GC, although, according to current guidelines, the standard for recurrent and metastatic GC is chemotherapy $[2,3]$. The median overall survival (OS) for patients with unresectable GC remains 8-16 months [4-7]. Recently, in the reductive gastrectomy for advanced tumor in three Asian countries (REGATTA) trial conducted by the Japan Clinical Oncology Group (JCOG) and the Korean Gastric Cancer Association (KGCA), no survival benefit of reductive gastrectomy followed by chemotherapy compared with chemotherapy alone was reported for patients with advanced GC with a single noncurable factor [8], demonstrating that more effective treatment strategies are required to improve survival in this population $[9,10]$.

The liver is the most common site of hematogenous metastasis from GC. Liver metastases (LM) from GC (LMGC) are diagnosed synchronously in $3-14 \%$ of patients with GC and metachronously in as many as $37 \%$ after curative gastrectomy [11, 12]. In contrast to LM from colorectal cancer, patients with LMGC have not been recommended to be candidates for surgery because of a high rate of simultaneous peritoneal seeding or extensive lymph node metastases [13].

However, a potential benefit of hepatectomy for a subpopulation of patients with LMGC has been reported in several studies within the past decade (Table 1). Even though almost all studies were small retrospective series, a limited number and small size of LM were favorable prognostic factors in patients who undergo hepatectomy. One multicenter retrospective analysis of 256 patients reported a promising median OS of 31.1 months [14]. A propensity-matched analysis using a national database in the United Kingdom showed that the prognosis of patients who underwent both gastrectomy and hepatectomy was better than of those who received no surgery [15]. The pooled analysis of nine retrospective studies in 679 patients indicated a potential survival benefit of surgery compared with chemotherapy alone $(\mathrm{HR}=0.50 ; 95 \% \mathrm{CI}$, $0.41-0.61$ ) [16]. Although the retrospective nature of these studies limits their value for clinical recommendations, it appears that there is a potential benefit of surgery for subpopulations of patients with LMGC. However, there are several unresolved clinical questions, such as the optimal indication for surgery and the role of preoperative or postoperative chemotherapy. The clinical outcome after hepatectomy alone is still poor, with a 5-year survival rate as low as $15-30 \%$. In view of the dismal prognosis of patients with LMGC, there is an urgent medical need to develop more efficient treatment strategies.
For this reason, the EORTC GITCG and JCOG SCSG have decided to work together to develop a joint treatment strategy for LMGC. As an initial step, a center survey was conducted to establish what represents the standard or most commonly applied clinical practice in Europe and Japan. This article presents the results of this survey and delineates the vision to develop a joint treatment strategy for LMGC.

\section{The survey}

The survey was sent to the network of the EORTC GITCG and JCOG SCSG. The respondents were instructed to provide answers based on their institutional policies. Seven questions were posed, covering the following topics:

1. The treatment of patients with cT3N0 GC with synchronous $2-\mathrm{cm}$ solitary $\mathrm{LM}$ in a lateral liver segment.

2. The timing of surgery when both primary tumor and LM are present (this was asked for the sites that selected surgery in question 1).

3. The role of staging laparotomy/laparoscopy in synchronous LM.

4. The treatment of patients with two resectable metachronous LMGC in both lobes 2 years after curative gastrectomy.

5. The treatment of patients with ten unresectable metachronous LMGC in both liver lobes 2 years after curative gastrectomy.

6. Preferred first-line chemotherapy regimens for HER2negative metastatic GC.

7. The number of GC patients with liver-limited metastases in 2015.

The survey was initiated on 14 June 2016, and the date of data collection cutoff was 13 July 2016. All responses were collected and analyzed by K.K. and S.S. (staff at EORTC headquarters).

\section{Results}

Answers were collected from 67 sites (17 countries) in Europe and 55 sites in Japan (Supplemental Fig. 1). The answers are presented in Figs. 1, 2, and 3.

\section{Clinical practice for the treatment of synchronous resectable LMGC (questions 1-3)}

Figure 1a shows that $47.5 \%$ of the sites perform preoperative chemotherapy followed by gastrectomy and hepatectomy whereas only $16.4 \%$ of sites perform chemotherapy 


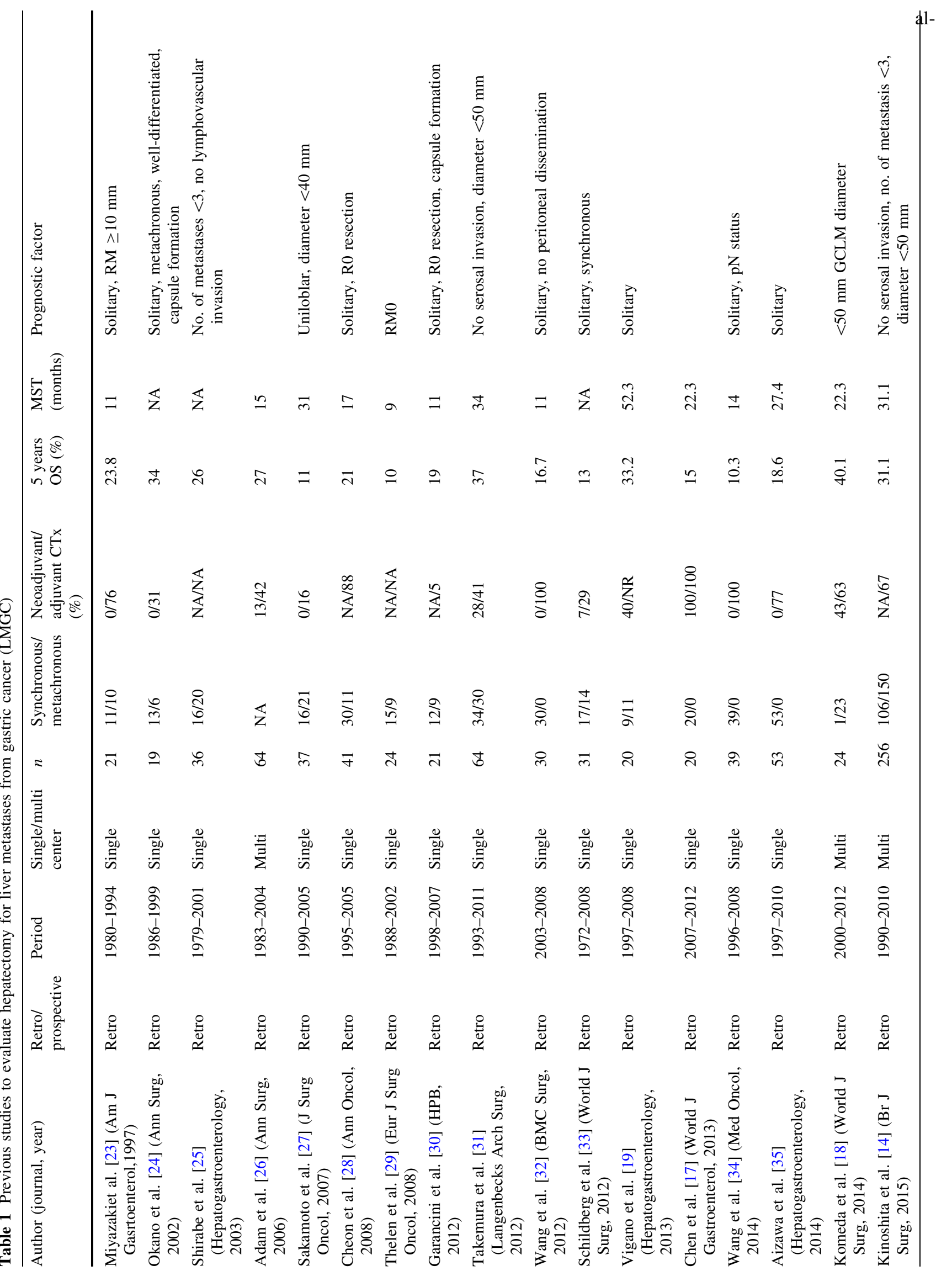


one. Twenty-two percent of the sites perform upfront gastrectomy and hepatectomy. Looking at differences between Europe and Japan (Fig. 1b), there is a tendency that European sites prefer chemotherapy alone compared to surgery alone (26.9\% vs. $7.5 \%)$ whereas the Japanese sites prefer upfront surgery compared to chemotherapy alone (40.0\% vs. $3.6 \%$ ). Regarding the timing of resection of the primary and LM, $89 \%$ of the sites perform gastrectomy and hepatectomy at the same time. Staging laparoscopy/laparotomy is performed at only half the sites for this situation.

\section{Clinical practice for the treatment of metachronous resectable LMGC (question 4)}

As with synchronous disease, preoperative chemotherapy followed by surgery is the preferred option in cases of metachronous LMGC. Figure 2 a shows that $50.4 \%$ of the sites are treating patients with preoperative chemotherapy followed by hepatectomy, and $24 \%$ of the sites prefer chemotherapy alone. Radiofrequency ablation (RFA) is performed in $10 \%$ of the sites if the maximal diameter of the liver metastasis is less than $3 \mathrm{~cm}$. When focusing on European sites, $33.3 \%$ and $30.3 \%$ choose preoperative chemotherapy followed by surgery and chemotherapy alone, respectively. For the Japanese sites, $70.9 \%$ and $16.4 \%$ choose preoperative chemotherapy followed by surgery and chemotherapy alone, respectively (Fig. 2b).

\section{Clinical practice for the treatment of unresectable LMGC (question 5)}

For unresectable LMGC, $85 \%$ of the sites perform chemotherapy alone (Supplemental Fig. 2). Conversion to resectable disease is not intended in most sites. No difference was seen between European and Japanese sites.

\section{Chemotherapy regimen (question 6)}

Platinum-based regimens are used at almost all sites, but the combinations vary among sites. Although regimens vary considerably among European countries, S-1 combined with oxaliplatin or cisplatin is preferred in almost all Japanese sites (Fig. 3).

\section{Number of LMGC patients treated per year (question 7)}

The median number of LMGC patients (without extrahepatic disease) treated in each site is 5 (range, 0-50). About $75 \%$ of the sites treat at most 5 LMGC patients per year. 
Fig. 1 Clinical practice for a patient with gastric cancer with synchronous solitary liverlimited metastasis: all sites (a) and sites in Europe and Japan (b)

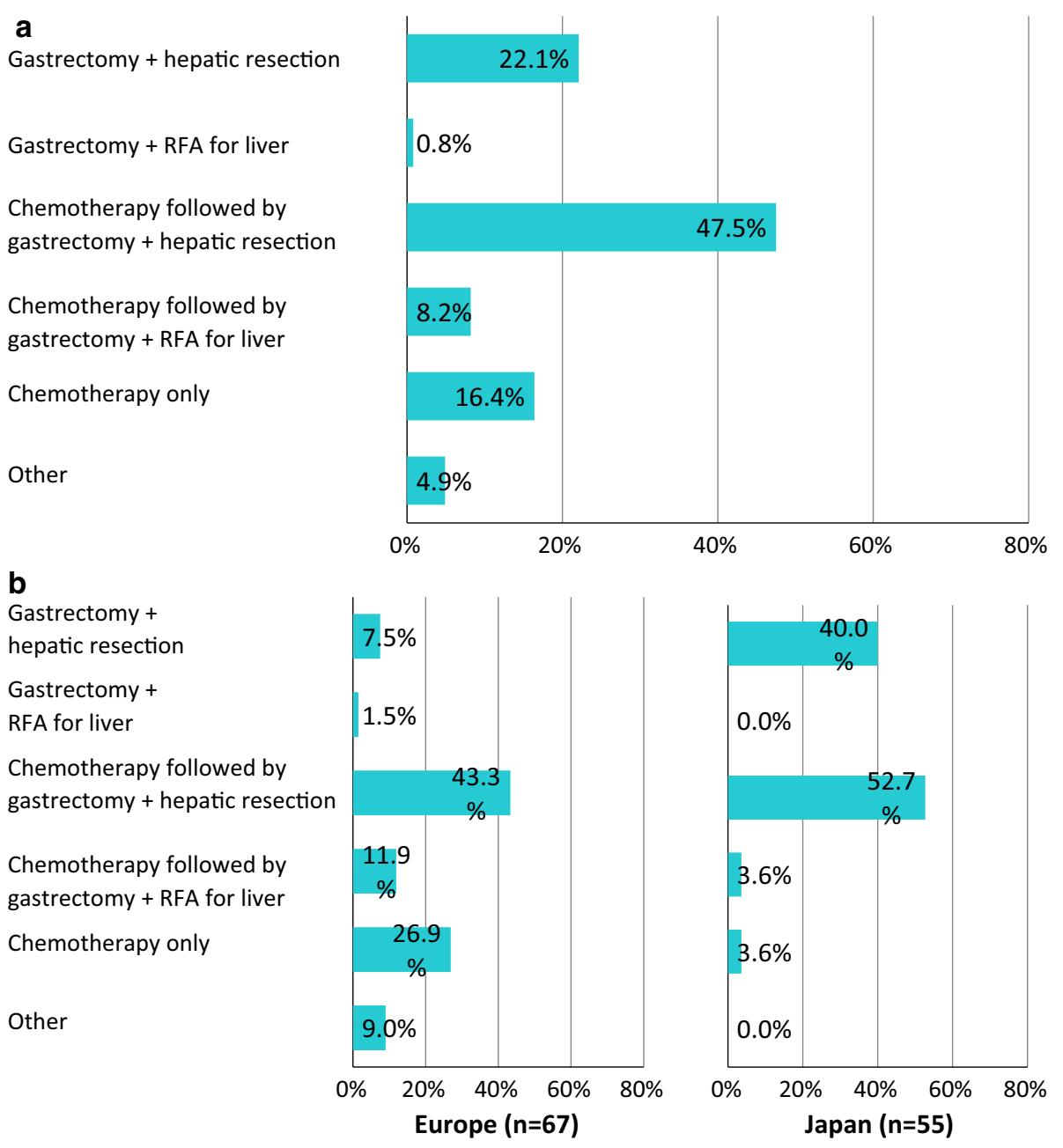

\section{What is the next step?}

Three treatment options are mainly considered for resectable LMGC according to the survey: (1) chemotherapy alone, (2) upfront surgery, and (3) preoperative chemotherapy followed by surgery. Preoperative chemotherapy followed by surgery is the preferred option for both synchronous and metachronous resectable LMGC. Although chemotherapy alone is the recommended standard of care for LMGC patients in the guidelines [2, 3], the strategy of preoperative chemotherapy followed by surgery should be further explored for resectable LMGC. Regarding unresectable LMGC, most of the sites perform chemotherapy only. However, with the future introduction of more effective chemotherapy, conversion strategies might occur. Thus, prospective data should be collected to build a basis for developing more effective treatment strategies for this population.

Several questions arise from the results of our survey. First, the efficacy and safety data of preoperative chemotherapy followed by surgery are still quite limited. The meta-analysis included only a few series investigating preoperative chemotherapy followed by surgery [17-19]. Evaluation of this approach by prospectively collected data is required because patients with disease progression during chemotherapy might have been excluded from the retrospective data analyses, biasing the reported study results. Second, it is not clarified whether we should differentiate the therapeutic approach between synchronous and metachronous LMGC. In the answers received from European sites, the treatment strategy is similar in synchronous and metachronous LMGC whereas upfront surgery is preferred in synchronous LMGC in Japan. As outlined in Table 1, some reports showed that synchronous disease is a prognostic factor, but this was not consistent. Because the condition is rare, we have to think carefully about whether the development of novel treatment strategies should be separated between synchronous and metachronous LMGC. The third question is the role of RFA, which is performed in about $10 \%$ of 
Fig. 2 Clinical practice for a patient with metachronous resectable liver metastasis after curative resection of the primary tumor: all sites (a) and sites in Europe and Japan (b) a

Hepatic resection

RFA if the size of liver metastasis is $<3 \mathrm{~cm}$

Chemotherapy followed by hepatic resection

Chemotherapy followed by RFA (size $<3 \mathrm{~cm}$ )

Chemotherapy only

Other

b

Hepatic resection

RFA if the size of liver

metastasis is $<3 \mathrm{~cm}$

Chemotherapy followed by hepatic resection

Chemotherapy followed by RFA (size $<3 \mathrm{~cm}$ )

Chemotherapy only

Other
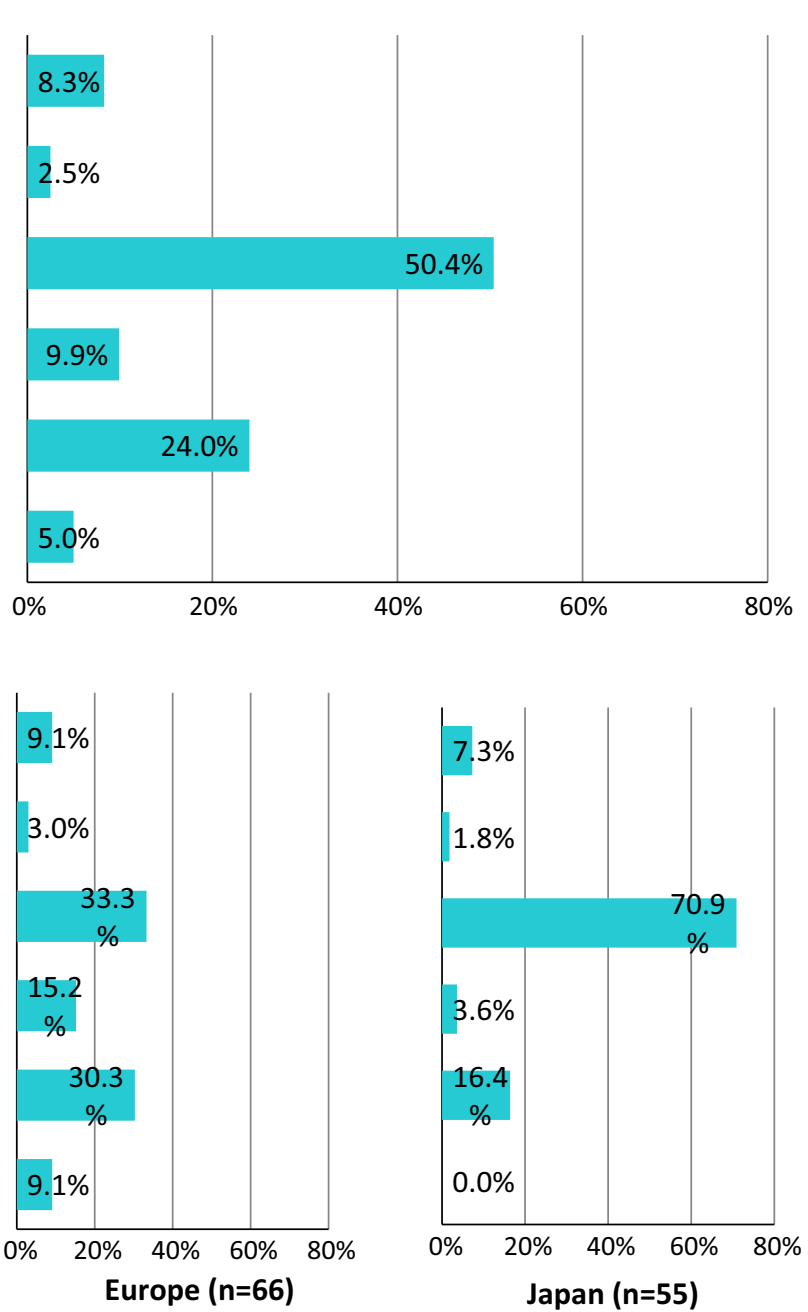

metachronous LMGC patients according to our survey. In addition, limited retrospective series indicate a potential benefit of RFA for LMGC [20, 21]. Taking into account that RFA is less invasive than surgery and that the treatment indication of RFA for colorectal LM has been expanding [22], treatment strategies including RFA should also be investigated.

So far, only one randomized controlled study is currently addressing the role of surgery for patients with metastatic GC. The FLOT 5 study is now investigating the superiority of chemotherapy plus surgery compared with chemotherapy alone for patients with limited metastatic GC or esophagogastric junction (NCT02578368). Of note, this trial allows metastatic lesions aside from LMGC. In REGATTA [8], only $9 \%$ of the metastatic GC patients presented with LM only. EORTC GITCG and JCOG SCSG are now working together to develop a more efficacious multidisciplinary treatment strategy for LMGC. The exact design of the new collaboration project is still under discussion. Although this survey showed some difference in preferred treatment strategies, and some difficulties in harmonizing scientific aspects such as the diagnostic procedure, chemotherapy regimen, and surgical procedures are anticipated, we agree to collaborate to improve the outcome of LMGC patients because the prognosis is still not sufficient. Currently, we are discussing the initiation of an interventional study on perioperative chemotherapy and hepatectomy with additional use of an investigational compound that may enhance the anti-tumor activity of perioperative treatment for LMGC patients. In parallel, an observational cohort in the form of a registry trial is planned to allow for better insights about what is done in clinical practice. Taking into account the need for international cooperation in this important field, this study should be led by large cancer research organizations such as EORTC and JCOG [39] to enable faster recruitment and wider generalizability of findings. 


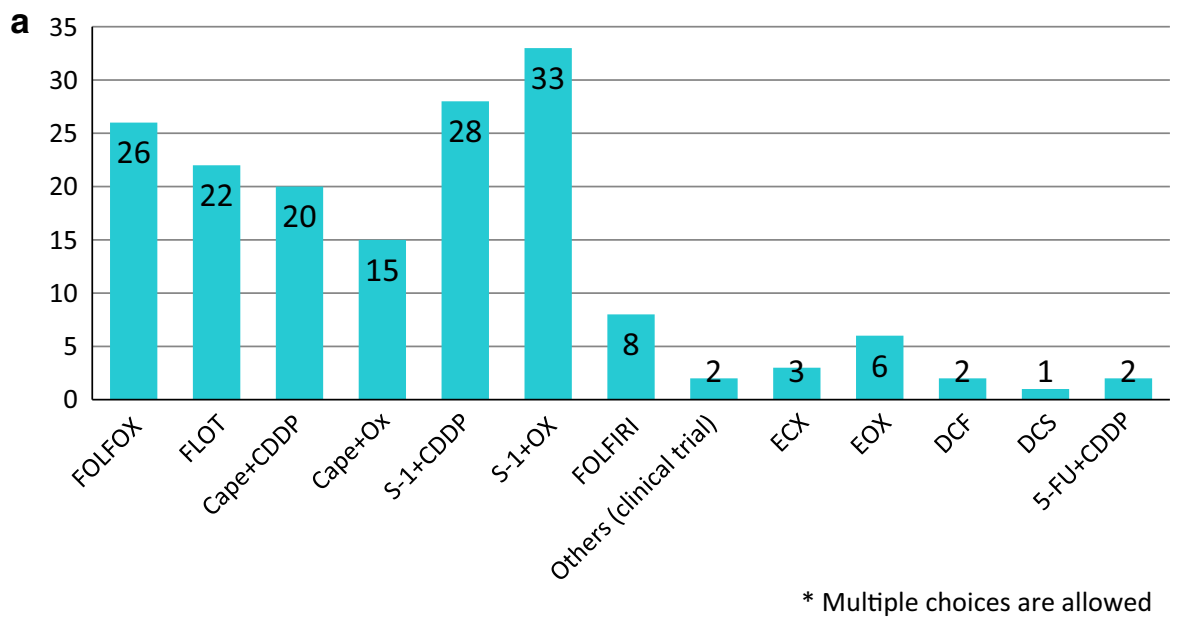

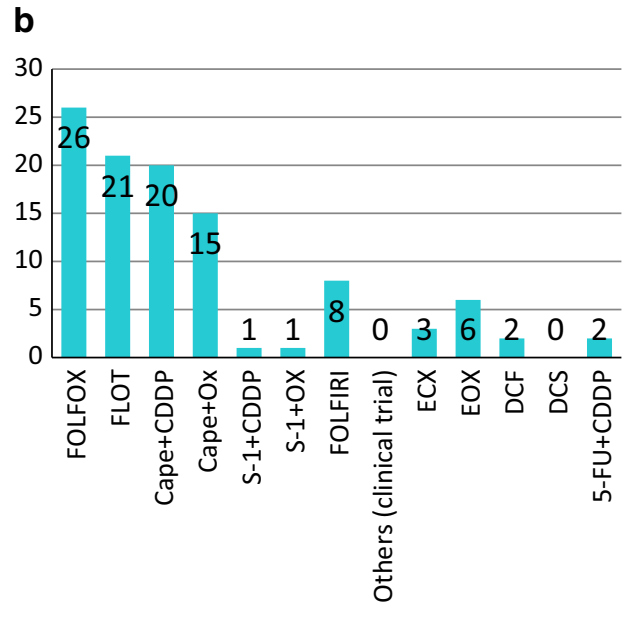

Europe

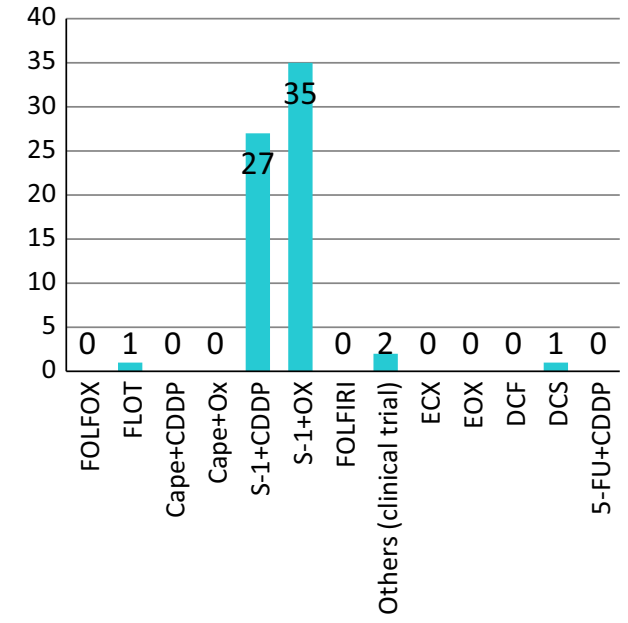

Japan

Fig. 3 Preferred first-line chemotherapy regimens for HER2-negative gastric cancer in the metastatic setting: all sites (a) and sites in Europe and Japan (b)

Acknowledgements The authors thank EORTC GITCG and JCOG SCGC participating sites for completing the survey, and Vinciane Vinckx of the EORTC headquarters for organizing the questionnaire. The fellowship of Kozo Kataoka is supported by FONDS Cancer (FOCA). This work is supported by Global Clinical Trial Development Project of Japan Agency for Medical Research and Development, AMED (16lk1203001j0001). The National Cancer Center Hospital, which also functions as the headquarters of the Japan Clinical Oncology Group, is appointed as Global Clinical Trial Core Centers of AMED.

\section{Compliance with ethical standards}

Conflict of interest Florian Lordick is an advisory for BioNTech, Bristol-Myers-Squibb, Eli Lilly, GANYMED Pharmaceuticals, Merck Sharp \& Dohme, Roche Pharma AG. He received lecture honoraria from Amgen, Astra Zeneca, Eli Lilly, Merck Sharp \& Dohme, Roche Pharma AG. He has research grants from Boehringer Ingelheim, Fresenius Biotech and received travel grants from Amgen, Bayer, Merck Sharp \& Dohme, Roche Pharma AG, Taiho Pharmaceutical. Anna Dorothea Wagner is a consultant for Eli Lily, Roche, Merck, Celgene, Bayer, Taiho. She receives lecture fees from Lilly and Celgene, travel grants from MSD, Lilly, Bayer, Janssen, and research grants from Roche. Takaki Yoshikawa plays an advisory role for MSD, Novartis, and Ono. He received lecture honoraria from Chugai, Taiho, Yakult, Eli Lilly, Nihon Kayaku, Ono, Takeda, Daiichi-Sankyo, Johnson and Johnson, Covidien, Olympus, Abbott, and Ajinomoto. He has a research grant from Chugai, Novartis, Yakult, and Taiho. Masanori Tokunaga received lecture honoraria from Eli Lilly, Kaken, Johnson and Johnson, and Covidien. The other authors have no conflict of interest regarding this work.

Human rights statement and informed consent All the questions asked in this survey were about the preference of the clinical practice of each investigator. Any patient information such as names, initials, addresses, admission dates, hospital numbers, or any other data that might identify patients were not asked or included in this survey.

\section{References}

1. International Agency for Research on Cancer. No title. GLOBOCAN 2012 Estim Cancer Incid Mortal Preval Worldw 201. 2012. http://globocan.iarc.fr/Default.aspx. 
2. Smyth EC, Verheij M, Allum W, Cunningham D, Cervantes A, Arnold D. Gastric cancer: ESMO Clinical Practice Guidelines for diagnosis, treatment and follow-up. Ann Oncol. 2016;27(suppl 5):v38-49. doi:10.1093/annonc/mdw350.

3. Japanese Gastric Cancer Association. Japanese classification of gastric carcinoma: 3rd English edition. Gastric Cancer. 2011;14(2):101-112. doi:10.1007/s10120-011-0041-5.

4. Ajani JA, Rodriguez W, Bodoky G, et al. Multicenter phase III comparison of cisplatin/S-1 with cisplatin/infusional fluorouracil in advanced gastric or gastroesophageal adenocarcinoma study: the FLAGS trial. J Clin Oncol. 2010;28(9):1547-53. doi:10.1200/ JCO.2009.25.4706.

5. Bang Y-J, Van Cutsem E, Feyereislova A, et al. Trastuzumab in combination with chemotherapy versus chemotherapy alone for treatment of HER2-positive advanced gastric or gastro-oesophageal junction cancer (ToGA): a phase 3, open-label, randomised controlled trial. Lancet. 2010;376(9742):687-97. doi:10. 1016/S0140-6736(10)61121-X.

6. Cunningham D, Starling N, Rao S, et al. Capecitabine and oxaliplatin for advanced esophagogastric cancer. N Engl J Med. 2008;358(1):36-46. doi:10.1056/NEJMoa073149.

7. Koizumi W, Narahara H, Hara T, et al. S-1 plus cisplatin versus S-1 alone for first-line treatment of advanced gastric cancer (SPIRITS trial): a phase III trial. Lancet Oncol. 2008;9(3):215-21. doi:10.1016/S1470-2045(08)70035-4.

8. Fujitani K, Yang H-K, Mizusawa J, et al. Gastrectomy plus chemotherapy versus chemotherapy alone for advanced gastric cancer with a single non-curable factor (REGATTA): a phase 3, randomised controlled trial. Lancet Oncol. 2016;17(3):309-18. doi:10.1016/S1470-2045(15)00553-7.

9. Shen L, Shan Y-S, Hu H-M, et al. Management of gastric cancer in Asia: resource-stratified guidelines. Lancet Oncol. 2013;14(12):e535-47. doi:10.1016/S1470-2045(13)70436-4.

10. Lordick F, Siewert JR. Recent advances in multimodal treatment for gastric cancer: a review. Gastric Cancer. 2005;8(2):78-85. doi:10.1007/s10120-005-0321-z.

11. Saiura A, Umekita N, Inoue $S$, et al. Clinicopathological features and outcome of hepatic resection for liver metastasis from gastric cancer. Hepatogastroenterology. 2002;49(46):1062-5.

12. Zacherl J, Zacherl M, Scheuba C, et al. Analysis of hepatic resection of metastasis originating from gastric adenocarcinoma. J Gastrointest Surg. 2002;6(5):682-9.

13. D'Angelica M, Gonen M, Brennan MF, Turnbull AD, Bains M, Karpeh MS. Patterns of initial recurrence in completely resected gastric adenocarcinoma. Ann Surg. 2004;240(5):808-16.

14. Kinoshita T, Kinoshita T, Saiura A, Esaki M, Sakamoto H, Yamanaka T. Multicentre analysis of long-term outcome after surgical resection for gastric cancer liver metastases. Br J Surg. 2015;102(1):102-7. doi:10.1002/bjs.9684.

15. Markar SR, Mackenzie H, Mikhail S, et al. Surgical resection of hepatic metastases from gastric cancer: outcomes from national series in England. Gastric Cancer. 2016;. doi:10.1007/s10120016-0604-6.

16. Markar SR, Mikhail S, Malietzis G, et al. Influence of surgical resection of hepatic metastases from gastric adenocarcinoma on long-term survival: systematic review and pooled analysis. Ann Surg. 2016;263(6):1092-101. doi:10.1097/SLA. 0000000000001542 .

17. Chen L, Song M-Q, Lin H-Z, et al. Chemotherapy and resection for gastric cancer with synchronous liver metastases. World J Gastroenterol. 2013;19(13):2097-103. doi:10.3748/wjg.v19.i13. 2097.

18. Komeda K, Hayashi M, Kubo S, et al. High survival in patients operated for small isolated liver metastases from gastric cancer: a multi-institutional study. World J Surg. 2014;38(10):2692-7. doi:10.1007/s00268-014-2608-x.
19. Vigano L, Vellone M, Ferrero A, Giuliante F, Nuzzo G, Capussotti L. Liver resection for gastric cancer metastases. Hepatogastroenterology. 2013;60(123):557-62. doi:10.5754/hge11187.

20. Guner A, Son T, Cho I, et al. Liver-directed treatments for liver metastasis from gastric adenocarcinoma: comparison between liver resection and radiofrequency ablation. Gastric Cancer. 2016;19(3):951-60. doi:10.1007/s10120-015-0522-z.

21. Chen J, Tang Z, Dong X, et al. Radiofrequency ablation for liver metastasis from gastric cancer. Eur J Surg Oncol. 2013;39(7):701-6. doi:10.1016/j.ejso.2013.03.023.

22. Ruers T, Punt C, Van Coevorden F, et al. Radiofrequency ablation combined with systemic treatment versus systemic treatment alone in patients with non-resectable colorectal liver metastases: a randomized EORTC Intergroup phase II study (EORTC 40004). Ann Oncol. 2012;23(10):2619-26. doi:10.1093/annonc/mds053.

23. Miyazaki M, Itoh $H$, Nakagawa $K$, et al. Hepatic resection of liver metastases from gastric carcinoma. Am J Gastroenterol. 1997;92(3):490-493.

24. Okano K, Maeba T, Ishimura K, et al. Hepatic resection for metastatic tumors from gastric cancer. Ann Surg. 2002;235(1):86-91.

25. Shirabe K, Shimada M, Matsumata $T$, et al. Analysis of the prognostic factors for liver metastasis of gastric cancer after hepatic resection: a multi-institutional study of the indications for resection. Hepatogastroenterology. 2003;50(53):1560-1563.

26. Adam R, Chiche L, Aloia T, et al. Hepatic resection for noncolorectal nonendocrine liver metastases: analysis of 1,452 patients and development of a prognostic model. Ann Surg. 2006;244(4):524-535. doi:10.1097/01.sla.0000239036.46827.5f.

27. Sakamoto Y, Sano T, Shimada K, et al. Favorable indications for hepatectomy in patients with liver metastasis from gastric cancer. J Surg Oncol. 2007;95(7):534-539. doi:10.1002/jso.20739.

28. Cheon SH, Rha SY, Jeung H-C, et al. Survival benefit of combined curative resection of the stomach (D2 resection) and liver in gastric cancer patients with liver metastases. Ann Oncol. 2008;19(6):1146-1153. doi:10.1093/annonc/mdn026.

29. Thelen A, Jonas S, Benckert C, et al. Liver resection for metastatic gastric cancer. Eur J Surg Oncol. 2008;34(12):1328-1334. doi:10.1016/j.ejso.2008.01.022.

30. Garancini M, Uggeri F, Degrate L, et al. Surgical treatment of liver metastases of gastric cancer: is local treatment in a systemic disease worthwhile?. HPB (Oxford). 2012;14(3):209-215. doi:10. 1111/j.1477-2574.2011.00428.x.

31. Takemura N, Saiura A, Koga R, et al. Long-term outcomes after surgical resection for gastric cancer liver metastasis: an analysis of 64 macroscopically complete resections. Langenbecks Arch Surg. 2012;397(6):951-957. doi:10.1007/s00423-012-0959-z.

32. Wang Y-N, Shen K-T, Ling J-Q, et al. Prognostic analysis of combined curative resection of the stomach and liver lesions in 30 gastric cancer patients with synchronous liver metastases. BMC Surg. 2012;12:20. doi:10.1186/1471-2482-12-20.

33. Schildberg CW, Croner R, Merkel S, et al. Outcome of operative therapy of hepatic metastatic stomach carcinoma: a retrospective analysis. World J Surg. 2012;36(4):872-878. doi:10.1007/ s00268-012-1492-5.

34. Wang W, Liang H, Zhang H, Wang X, Xue Q, Zhang R. Prognostic significance of radical surgical treatment for gastric cancer patients with synchronous liver metastases. Med Oncol. 2014;31(11):258. doi:10.1007/s12032-014-0258-3.

35. Aizawa M, Nashimoto A, Yabusaki H, Nakagawa S, Matsuki A. Clinical benefit of surgical management for gastric cancer with synchronous liver metastasis. Hepatogastroenterology. 2014;61(133):1439-1445.

36. Oki E, Tokunaga S, Emi Y, et al. Surgical treatment of liver metastasis of gastric cancer: a retrospective multicenter cohort 
study (KSCC1302). Gastric Cancer. 2016;19(3):968-976. doi:10. 1007/s10120-015-0530-z.

37. Tatsubayashi T, Tanizawa Y, Miki Y, et al. Treatment outcomes of hepatectomy for liver metastases of gastric cancer diagnosed using contrast-enhanced magnetic resonance imaging. Gastric Cancer. 2016. doi:10.1007/s10120-016-0611-7.

38. Tiberio GAM, Baiocchi GL, Morgagni P, et al. Gastric cancer and synchronous hepatic metastases: is it possible to recognize candidates to R0 resection? Ann Surg Oncol. 2015;22(2):589-596. doi:10.1245/s10434-014-4018-6.

39. Kataoka K, Nakamura $\mathrm{K}$, Caballero $\mathrm{C}$, et al. Collaboration between EORTC and JCOG-how to accelerate global clinical research partnership. Jpn J Clin Oncol. 2016;. doi:10.1093/jjco/ hyw 159 . 